\title{
Correlation Between Compositional and Mechanical Properties of Human Mesenchymal Stem Cell-Collagen Microspheres During Chondrogenic Differentiation
}

\author{
Chun-hei Li, M.Phil., ${ }^{1,2}$ Tsz-Kit Chik, B.Eng., ${ }^{1,2}$ Alfonso H.W. Ngan, Ph.D., ${ }^{2}$ Stanley C.H. Chan, Ph.D., ${ }^{3}$ \\ Daisy K.Y. Shum, Ph.D., ${ }^{3}$ and Barbara P. Chan, Ph.D. ${ }^{1,2}$
}

Mesenchymal stem cell (MSC)-based engineering is promising for cartilage repair. However, the compositional mechanical relationship of the engineered structures has not been extensively studied, given the importance of such relationship in native cartilage tissues. In this study, a novel human MSC-collagen microsphere system was used to study the compositional mechanical relationship during in vitro chondrogenic differentiation using histological and biochemical methods and a microplate compression assay. The mechanical property was found positively correlating with newly deposited cartilage-relevant matrices, glycosaminoglycan, and type II collagen, and with the collagen crosslinker density, in agreement with the presence of thick collagen bundles upon structural characterization. On the other hand, the mechanical property negatively correlates with type I collagen and total collagen, suggesting that the initial collagen matrix scaffold of the microsphere system was being remodeled by the differentiating human MSCs. This study also demonstrated the application of a simple, sensitive, and nondestructive tool for monitoring the progression of chondrogenic differentiation of MSCs in tissue-engineered constructs and therefore contributes to future development of novel cartilage repair strategies.

\section{Introduction}

$\mathrm{C}^{2}$ ARTILAgE INJURIES are very common. Owing to the acellular and avascular nature, cartilage itself has very limited ability to repair and regenerate. ${ }^{1-5}$ Current treatments have obvious deficiencies. Arthroscopic techniques alleviate pain instead of regenerating the cartilage, ${ }^{4-8}$ and microfracture techniques lead to the formation of more vulnerable fibrocartilage. ${ }^{4,7,10}$ Autologous chondrocyte implantation $^{5,7,11}$ and autogenic or allogenic tissue transplantation ${ }^{4,5,7,11-13}$ have donor availability problem and donor-site morbidities. Therefore, better treatment options such as autologous stem cell-based therapies are needed.

Bone marrow mesenchymal stem cells (MSCs) are attractive cell source for tissue engineering. This is because of their relatively safe and easy accessibility from the donor, the ability of self-renewal and differentiating into multiple lineages of cells, ${ }^{14,15}$ genetic stability, immunologically privileged status, $^{14,16}$ and better social and ethics acceptability than embryonic stem cells. In MSC-based cartilage tissue engi- neering, these cells are expected to differentiate into chondrogenic lineages and then remodel the biodegradable scaffolds into a tissue structure simulating the native cartilage.

The compositional and mechanical relationship of native cartilage tissues has long been studied. ${ }^{17-19}$ The mechanical function performed by cartilage mainly associates with its resistance to compression. Compressive modulus, shear modulus, and Poisson's ratio of native cartilage have been found to associate with the amount of extracellular matrix (ECM), including collagen, ${ }^{1,2,17,18,20-22}$ collagen crosslinks, ${ }^{17,23-26}$ and proteoglycans, $1,5,27,28$ of the tissue. Such relationship is equally important in stem cell-based engineered tissues for better understanding of the mechanisms of matrix remodeling in different scaffold systems. Nevertheless, despite a large amount of studies using MSCs in different scaffolds for cartilage repair, ${ }^{29-31}$ the compositional mechanical relationship via matrix remodeling of engineered constructs are not extensively studied.

Previously, we have established a novel collagen microencapsulation technique ${ }^{32}$ to entrap cells such as MSCs, ${ }^{33,34}$ embryonic stem cells, ${ }^{35}$ chondrocytes, ${ }^{36}$ and HEK 293 cells $^{37,38}$

Part of this work has been presented in the TERMIS 2nd World Congress, Seoul, Korea, Aug 31 to Sep 3, 2009 (The Best Poster Presentation Award).

${ }^{1}$ Tissue Engineering Laboratory, Department of Mechanical Engineering, The University of Hong Kong, Hong Kong Special Administrative Region, China.

${ }^{2}$ Department of Mechanical Engineering, The University of Hong Kong, Hong Kong Special Administrative Region, China.

${ }^{3}$ Department of Biochemistry, Li Ka Shing Faculty of Medicine, The University of Hong Kong, Hong Kong Special Administrative Region, China. 
in microspheres made of dense fibrous type I collagen meshwork, which provides a suitable 3D matrix environment for cells to survive, proliferate, and migrate. ${ }^{33}$ Human MSCs (hMSCs) that resided in these microspheres were also proven to retain stem cell characteristics, including their immunophenotype, multipotent differentiating potential, and self-renewal capacity. ${ }^{33}$ Moreover, this microsphere system provides a template collagen fiber meshwork for both mature cells such as chondrocytes ${ }^{36}$ and differentiating stem cell such as embryonic stem cells ${ }^{35}$ and MSCs $^{34,39}$ to remodel upon chemical induction.

In this study, we hypothesize that the temporal changes of various compositional parameters would closely associate with the change in the mechanical parameter, namely, the elastic modulus of the microsphere during chondrogenic differentiation of the entrapped hMSCs. Specifically, we aim to characterize the in vitro chondrogenic differentiation of hMSCs in collagen microspheres and establish the association among different compositional parameter with the mechanical parameter. Specifically, reduced elastic modulus $\left(E_{\mathrm{r}}\right)$ of the microspheres will be measured using a microplate compression technique established in our lab. ${ }^{40}$ Cartilage-relevant ECM components, including collagen type II and glycosaminoglycans (GAGs), and pyridinoline (PYD) crosslink density will be assessed using both histological and biochemical methods. Correlation coefficients between various biochemical composition parameters and the mechanical parameter will be obtained. The significance of the established association between biochemical composition and mechanical property of the microsphere would help us to better understand how hMSC remodel the scaffold to form a cartilage-like structure during chondrogenic differentiation and therefore may contribute to future novel cartilage repair strategy.

\section{Materials and Methods}

\section{Overall research design}

hMSCs were microencapsulated in collagen microspheres and induced to differentiate toward chondrogenic lineages using a chemically defined culture medium. At different time points postdifferentiation, the microsphere populations were divided, pooled, and processed for histological, biochemical, structural, and mechanical characterization. Apart from routine histological staining, histochemical staining for GAGs and immunohistochemical staining for type I and II collagen were conducted. Quantitative measurements of the biochemical compositions of the microspheres, namely, hydroxyproline (HYP) for total collagen content, uronic acids for GAG content, type I and II collagen, and PYD collagen crosslinker, have been conducted using either chemical or immunochemical methods. Scanning electron microscopy (SEM) was also conducted to reveal the fibrous structures of the microspheres during chondrogenic differentiation. A microplate step-change compression assay has been used to measure the $E_{\mathrm{r}}$ of the microspheres. Finally, correlation coefficients between the biochemical compositional parameters and the mechanical parameter of the differentiating microspheres have been calculated.

\section{Culture of hMSCs}

hMSCs from bone marrow from three donors (male, age 47-49) were kindly provided by Dr. G.C.F. Chan from the Department of Paediatrics and Adolescent Medicine of the same institution. hMSCs were isolated and cultured as previously described. ${ }^{41}$ All procedures were approved by the Combined Clinical Ethics Committee of the University of Hong Kong and Hong Kong West Cluster Hospitals of Hospital Authority. In brief, the cells were cultured in the growth medium containing Dulbecco's modified Eagle's mediumlow glucose (Gibco), 10\% fetal bovine serum (Gibco), $100 \mathrm{U} /$ $\mathrm{mL}$ penicillin (Gibco), $100 \mu \mathrm{g} / \mathrm{mL}$ streptomycin (Gibco), and $2 \mathrm{mM}$ L-glutamine (Gibco), incubated at $37^{\circ} \mathrm{C}$ in a humidified atmosphere with $5 \% \mathrm{CO}_{2}$. The culture medium was replaced every 3-4 days. The cells were subcultured up to passage 6 for fabrication of microspheres. Immunophenotype, self-renewal capacity, and multidifferentiating potential of the hMSCs were characterized in a previous study. ${ }^{33}$

\section{Fabrication of collagen-hMSC microspheres}

Collagen-hMSC microspheres were fabricated as previously described ${ }^{33}$ and fabrication parameters optimized as reported elsewhere. ${ }^{34}$ In brief, cell suspension was mixed with neutralized rat tail type I collagen solution (BD Biosciences) in an ice bath. The cell-collagen mixture was diluted by the culture medium to a final cell density of $1 \times 10^{6}$ cells / $\mathrm{mL}$ and a final collagen concentration of $1 \mathrm{mg} / \mathrm{mL}$. Droplets of the mixture in volumes of $50 \mu \mathrm{L}$ and $100 \mu \mathrm{L}$ were pipetted onto UV-irradiated parafilm placed in separate Petri dishes. The $100 \mu \mathrm{L}$ droplets were used to produce microspheres of larger sizes to ease the sample preparation process for SEM analysis. Gelation of the collagen-hMSC droplets was brought about by incubation at $37^{\circ} \mathrm{C}$ in a humidified atmosphere consisting of $5 \% \mathrm{CO}_{2}$ for $45 \mathrm{~min}$. The gelated droplets were then cultured in the same medium for 5 days to allow for cell-induced contraction. Microspheres made from $50 \mu \mathrm{L}$ droplets were used for subsequent biomechanical, biochemical, and histological studies, whereas those made from $100 \mu \mathrm{L}$ droplets were used for ultrastructural study.

\section{Chondrogenic differentiation of hMSCs in collagen microspheres}

Chondrogenic differentiation of hMSCs encapsulated in the collagen microspheres was brought about by culturing the collagen-hMSC microspheres in the chondrogenic differentiation induction medium, defined as Dulbecco's modified Eagle's medium-high glucose, with the supplementation of $10 \mathrm{ng} / \mathrm{mL}$ recombinant human TGF- $\beta 3$ (Preprotech), $100 \mathrm{nM}$ dexamethasone (Sigma-Aldrich), $0.1 \mathrm{nM} \mathrm{L-ascorbic} \mathrm{acid}$ 2-phosphate (Fluka), $6 \mathrm{mg} / \mathrm{mL}$ insulin (Merck), $6 \mu \mathrm{g} / \mathrm{mL}$ transferring (Sigma), $1 \mathrm{mM}$ sodium pyruvate (Gibco), $0.35 \mathrm{mM}$ L-proline (Merck), and $1.25 \mathrm{mg} / \mathrm{mL}$ bovine serum albumin (Sigma). The medium was changed every 2 days and lasted for 3 weeks. Microspheres were harvested on days 0, 7, 14, and 21 upon the addition of chondrogenic differentiation induction medium for subsequent analyses. Cell-free collagen microspheres can also be used as the control, but these microspheres disintegrated and therefore weakened over time such that subsequent analyses could not be performed.

\section{Histological, histochemical, and immunohistochemical staining of ECM components}

Harvested microspheres were fixed in $4 \%$ phosphatebuffered saline (PBS)-buffered paraformaldehyde (BDH), 
paraffin embedded, and sectioned at $5 \mu \mathrm{m}$ thickness. Routine hematoxylin and eosin staining was performed to reveal cell morphology. Alcian blue histochemical staining was performed to observe the presence of GAGs. Immunohistochemical analysis was performed for type I and type II collagen, using primary mouse monoclonal antibodies against type I collagen (Sigma) and type II collagen (EMD), respectively. These antibodies exhibited cross-reactivity with human samples. After overnight incubation with the primary antibodies at $4{ }^{\circ} \mathrm{C}$, sections were incubated with antimouse secondary antibodies (Dako). The incubation lasted for $30 \mathrm{~min}$ at room temperature, followed by another $30 \mathrm{~min}$ with avidin-biotin-peroxidase complex (Vector Laboratories). Immunostaining was detected colorimetrically using diaminobenzidine (Dako). Sections were counterstained with hematoxylin.

\section{Quantitative measurement of ECM components}

Uronic acid analysis was adopted instead of the widely used 1,9-dimethylmethylene blue (DMMB) assay. Uronic acid is a regular component of disaccharide repeating units of chondoroitin sulfates and hyaluronans, major GAGs found in the ECM of articular cartilage. ${ }^{42}$ This assay offers an advantage over the DMMB assay because it is independent of the GAG size and the degree of sulfation. ${ }^{43}$ In brief, each microsphere was digested overnight at $60^{\circ} \mathrm{C}$ with $300 \mu \mathrm{g} / \mathrm{mL}$ papain (Sigma) in $50 \mathrm{mM}$ phosphate buffer (Sigma; $\mathrm{pH}$ 6.5) containing $5 \mathrm{mM}$ L-cysteine (Calbiochem) and $5 \mathrm{mM}$ ethylenediaminetetraacetic acid (Sigma), followed by sequential precipitation at $4{ }^{\circ} \mathrm{C}$ in $0.5 \%$ cetylpyridinium chloride (Sigma) in $0.025 \mathrm{M}$ acetate buffer ( $\mathrm{pH}$ 5.8; Sigma), and then sodium acetate-saturated ethanol. The dried GAG product was dissolved in a defined volume distilled water for the assay. ${ }^{44}$ Procedures for uronic acid analysis were described elsewhere. ${ }^{43}$ Briefly, $200 \mu \mathrm{L}$ of $0.025 \mathrm{M}$ di-sodium tetraborate 10 hydrate (Merck) in concentrated sulfuric acid was added to each precooled test GAG solution and then heated at $100^{\circ} \mathrm{C}$ for $10 \mathrm{~min}$. Twenty microliters of $0.125 \%$ carbazole (Eastman Kodak) in absolute ethanol was then added to each of the cooled mixtures and heated at $100^{\circ} \mathrm{C}$ for another $15 \mathrm{~min}$ to produce the colored product. After cooling to room temperature, the optical density of the product was read at $530 \mathrm{~nm}$ with a microplate reader. Optical densities of standard glucuronic acid (Sigma) with different concentrations were plotted in a standard curve. Hexuronic acid content of the test sample was determined from the standard curve after correction for dilution effects.

HYP assay was used to determine the content of HYP, which is the marker for total collagen, presented in the microspheres as described previously. ${ }^{45,46}$ In brief, 10 microspheres at each time point were pooled together and hydrolyzed in $200 \mu \mathrm{L}$ of $6 \mathrm{~N}$ hydrochloric acid (Sigma) at $110^{\circ} \mathrm{C}$ for $18 \mathrm{~h}$ in a hydrolysis tube (Pierre) after being flushed with nitrogen gas for $30 \mathrm{~s}$. The acid hydrolyzate was neutralized by $6 \mathrm{~N}$ sodium hydroxide $(\mathrm{NaOH})$. One hundred microliters of neutralized acid hydrolysate ( $\mathrm{pH}$ 6-7) was added to a 96-well plate and oxidized by $50 \mu \mathrm{L} 0.05 \mathrm{M}$ chloramine T (Sigma) for $20 \mathrm{~min}$, followed by incubating with $50 \mu \mathrm{L}$ $3.15 \mathrm{M}$ perchloric acid (Sigma) for $5 \mathrm{~min}$. Oxidized samples were then mixed with $50 \mu \mathrm{L} p$-dimethylaminobenzaldehyde $\left(20 \%, \mathrm{w} / \mathrm{v}\right.$; Sigma) and incubated at $60^{\circ} \mathrm{C}$ for $20 \mathrm{~min}$ to produce coloured products. The optical densities of the assayed samples were measured at $557 \mathrm{~nm}$ with a microplate reader. HYP content was computed by linear interpolation using trans-4-hydroxy-L-Proline (Sigma) as standard.

Collagen type II enzyme-linked immunosorbent assay (ELISA; MD Bioscience) was used to determine the amount of type II collagen presented in the microspheres. Twenty microspheres at each time point were pooled together and digested by pepsin in $0.5 \mathrm{~N}$ acetic acid (Sigma; collagen: pepsin $=10: 1, \mathrm{w} / \mathrm{w}$ ) to extract type II collagen. Pretreatment with $0.2 \mathrm{M} \mathrm{NaOH}$ was performed for samples harvested on days 14 and 21 at $4{ }^{\circ} \mathrm{C}$ for $24 \mathrm{~h}$ to remove any proteoglycans as it has been demonstrated to improve the collagen extraction efficiency. Pepsin was digested at $20^{\circ} \mathrm{C}$ for $18 \mathrm{~h}$ with constant stirring. Insoluble residues were separated by centrifugation at $15,000 \mathrm{rpm}$ for $15 \mathrm{~min}$ and supernatants were collected. $^{47}$ They were adjusted to $\mathrm{pH} 8.0$ with $1 \mathrm{M} \mathrm{NaOH}$, followed by the digestion using 1/10 starting volume of pancreatic elastase solution $(1 \mathrm{mg} / \mathrm{mL}$ in $1 \times \mathrm{TBS}, \mathrm{pH} 7.8-8.0$; Sigma) at $4^{\circ} \mathrm{C}$ overnight. Extracted type II collagen was measured according to the manufacturer's instructions. In brief, samples and standards were added to the supplied 96-well plate and incubated with the capture antibodies for $2 \mathrm{~h}$. The wells were then washed and loaded with biotinylated antibodies for another $2 \mathrm{~h}$, followed by a wash and incubation with streptavidin-horseradish peroxidase (HRP) for $30 \mathrm{~min}$. After all, the plate was washed again and incubated with tetramethylbenzidine (TMB) solution for $20 \mathrm{~min}$. Sulfuric acid was added as the final step to stop the reaction and obtain color products. Absorbance was read at $450 \mathrm{~nm}$. All the incubation steps were carried out at room temperature. Type II collagen was quantified by linear interpolation with the standard.

Rat collagen type I ELISA (Chondrex) was used to determine the amount of type I collagen presented in the microspheres. Five microspheres at each time point were pooled together for collagen extraction using the same protocol as stated above. Extracted type I collagen was accessed according to the manufacturer's instructions. In brief, samples and standards were added to the supplied 96-well plate precoated with capture antibodies and were incubated for $2 \mathrm{~h}$. The wells were then washed and loaded with detection antibodies for another $2 \mathrm{~h}$, followed by a wash and incubation with streptavidin peroxidase for $1 \mathrm{~h}$. Afterward, the plate was washed again and incubated with orthophenylene-diamine (OPD) solution for $30 \mathrm{~min}$. Sulfuric acid was added as the final step to stop the reaction and obtain colored products. Absorbance was read at $490 \mathrm{~nm}$. All the incubation steps were carried out at room temperature. Rat type I collagen was quantified by linear interpolation with the standard.

Metra ${ }^{\circledR}$ PYD ELISA kit (Quidel Corporation) was used to quantify the amount of PYD, which is one of the major collagen crosslinkers, ${ }^{23,48}$ presented in the microspheres. The acid hydrolyates obtained previously in HYP assay was used for PYD quantification, following the procedures instructed by the manufacturer. In brief, samples or standards were added to each well of the coated strips, followed by the addition of anti-pyridinium crosslinks antibodies conjugated to alkaline phosphate. The mixtures were incubated at $4{ }^{\circ} \mathrm{C}$ for $3 \mathrm{~h}$ in dark. Afterward, each well was washed and substrate solution containing ethanolamine and magnesium chloride was added. Incubation at room temperature for another $1 \mathrm{~h}$ was carried out and the substrate reaction was 
stopped afterward by $\mathrm{NaOH}$. Color products were produced and the absorbance was read at $405 \mathrm{~nm}$. The PYD amount was determined from the standard curve obtained.

\section{Measurement of elastic modulus of the microspheres}

A microplate rate-jump compression method ${ }^{40}$ was used to determine the $E_{\mathrm{r}}$ of the collagen-hMSC microspheres at different time points during chondrogenic differentiation. $E_{\mathrm{r}}$ is chosen because it reflects the elastic components and therefore the resilience of the structures, which is characteristic to cartilage tissue. In brief, custom-made rigid and flexible microplates were mounted onto the metal holders of two separately controlled micromanipulators (MP-285 motorized micromanipulator; Sutter Instrument). A microsphere was attached onto the rigid microplate for around $5 \mathrm{~min}$ to assure firm adhesion, followed by the compression in $1 \times$ PBS by the flexible microplate, which had been calibrated for stiffness $(k)$ using an electronic balance and a height gauge. ${ }^{40}$ A step change compression protocol was employed to impose a sudden change in displacement rate during the process so as to eliminate the viscous component of the viscoelastic deformation of the microsphere. ${ }^{40,49}$ Sixty percent strain (i.e., $60 \%$ of the diameter of the microsphere in the compression axis) was set to be the displacement at the fixed end of the flexible microplate $(\delta)$. The compression started off with an initial displacement rate $\left(\dot{\delta}_{-}\right)$of $1 \mu \mathrm{m} / \mathrm{s}$, followed by a sudden change to $2 \mu \mathrm{m} / \mathrm{s}\left(\dot{\delta}_{+}\right)$upon reaching half of $\delta$. The whole compression process was captured by a digital camera (CoolSNAP ES; Photometrics) and the image was analyzed by image analysis software Metamorph (Molecular Devices Corporation). The free end displacement $\left(\delta^{\prime}\right)$ of the flexible microplate was tracked by the object tracking module of the software and the radius $(a)$ in the contact region between the two bodies was measured. $E_{\mathrm{r}}$ was calculated using the equation $E_{r}=\frac{E}{1-v^{2}}=\frac{k}{a}\left(\frac{\Delta \dot{\delta}}{\Delta \dot{\delta}^{\prime}}-1\right)$, where $\Delta \dot{\delta}$ and $\Delta \dot{\delta}^{\prime}$ represent the displacement rate change for the fixed and free end of the flexible microplate, respectively, at the time the sudden displacement rate change was imposed.

\section{Size measurement of microspheres during chondrogenic differentiation}

To estimate the effect of cells-induced contraction, the sizes of 36-40 microspheres at each time point during differentiation were measured using Metamorph. As the microsphere was not perfectly spherical, its dimensions parallel and perpendicular to the axis of compression were recorded. The mean of the two parameters was taken to be the effective dimension of the microsphere.

\section{SEM analysis of the microspheres}

SEM was used to examine the ultra-structure of collagenhMSC microspheres. Microspheres harvested at different time points were rinsed with $1 \times \mathrm{PBS}$ and fixed by $2.5 \%$ glutaraldehyde (Sigma) for $2 \mathrm{~h}$ at room temperature. They were then dehydrated through a graded series of ethanol (50\%, 70\%, 80\%, 90\%, 95\%, and 100\% for twice) and then critical point dried. The dried samples were fractured using a sharp blade to expose their cross sections and were mounted onto a metal stub using carbon cement. The samples were sputtered with gold for $20 \mathrm{~s}$ for electrical conductance during SEM examination.

\section{Statistical analysis}

Differences on microsphere dimension was analyzed by one-way analysis of variance (ANOVA) with Bonferroni's post-hoc test while those on $E_{\mathrm{r}}$, GlcUA, HYP, PYD, and collagen type I and II of the microspheres at different time points of differentiation and in different subjects were analyzed using two-way ANOVA (General Linear Model, Univariate) with Bonferroni's post-hoc tests. Nonparametric Spearman's Rho correlation coefficients between various biochemical compositional parameters and the mechanical property $E_{\mathrm{r}}$ of the microspheres in each subject were used to reveal their association during differentiation. Nonparametric tests were used because sample size per subject was small. All statistical tests were performed using SPSS 17.0 (SPSS). A significance level was set at 0.05 . Values were reported as mean \pm standard deviation unless otherwise specified.

\section{Results}

\section{Reduction in size of microspheres}

Upon chondrogenic differentiation, the hMSC-encapsulated collagen microspheres contracted over time (Fig. 1A-D). Their sizes decreased significantly by half on day 7 (Fig. 2A), whereas subsequent decline at 14 and 21 day postdifferentiation was no longer significant. One-way ANOVA with Bonferroni post-hoc test showed significant differences between all time point and day $0(p<0.05)$.

\section{Decrease in type I collagen and total collagen}

Type I collagen has great homology across different species. The antibody used for immunohistochemistry reacts with both human and rat type I collagen. As a result, type I collagen detected by immunohistochemistry include both rat type I collagen in the template and the newly synthesized human type I collagen if any. As shown in Figure $1 \mathrm{E}-\mathrm{H}$, immunopositive staining was found at all time points. Type I collagen was largely homogeneous throughout the microsphere before chondrogenic differentiation (Fig. 1E). Thick bundle-like immunonegative structures were detected at day 7 and 14 postdifferentiation (Fig. 1F, F1, G), whereas nodules with immunonegative staining could be found throughout the microsphere in these samples. At 21 days postdifferentiation, further increase in regions with immunonegative staining was detected particularly at the center (Fig. 1H). This decreasing trend was revealed by quantitative measurement of type I collagen in all three subjects using ELISA (Fig. 2B). Two-way ANOVA showed that the time factor $(p=0.001)$ but not the subject factor $(p=0.107)$ significantly affected type I collagen. Bonferroni's post-hoc tests on the time factor showed that day 21 was significantly different from day 0 and $7(p \leq 0.009)$ and day 14 was significantly different from day $7(p=0.009)$. HYP is the marker for total collagen including type I collagen used for fabrication of the microspheres and other types of collagen newly synthesized by the differentiating hMSCs. As shown in Figure 2C, the total collagen content decreases progressively during the chondrogenic differentiation 
Day 0

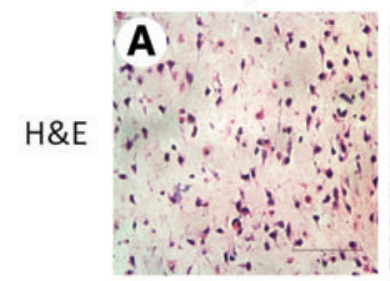

Coll
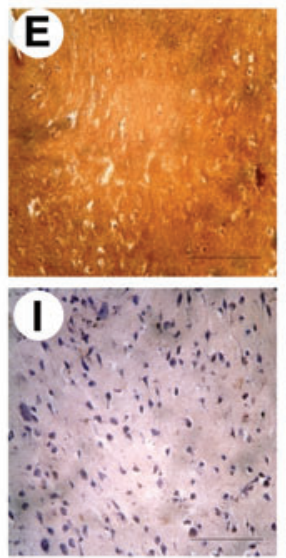

CollI

$A B$

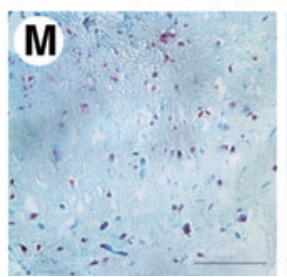

Day 7
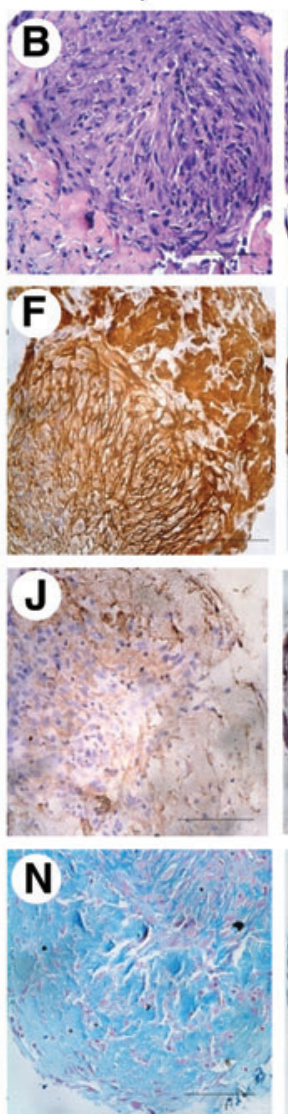

Day 14
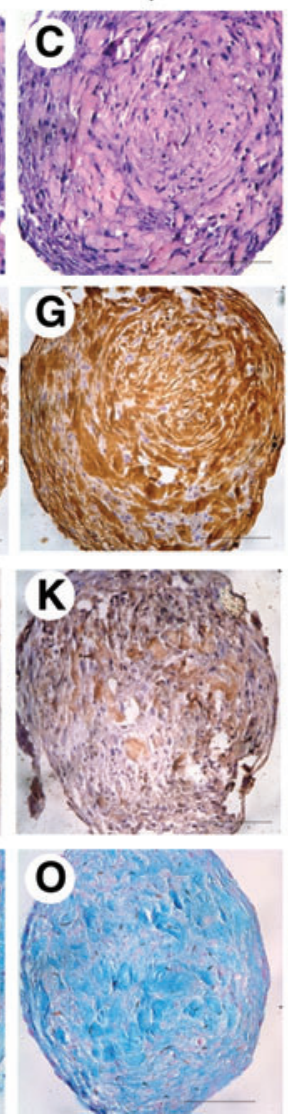

Day 21
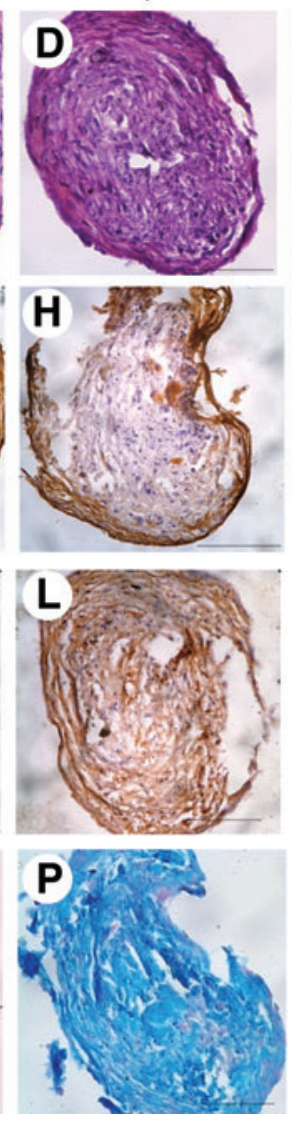
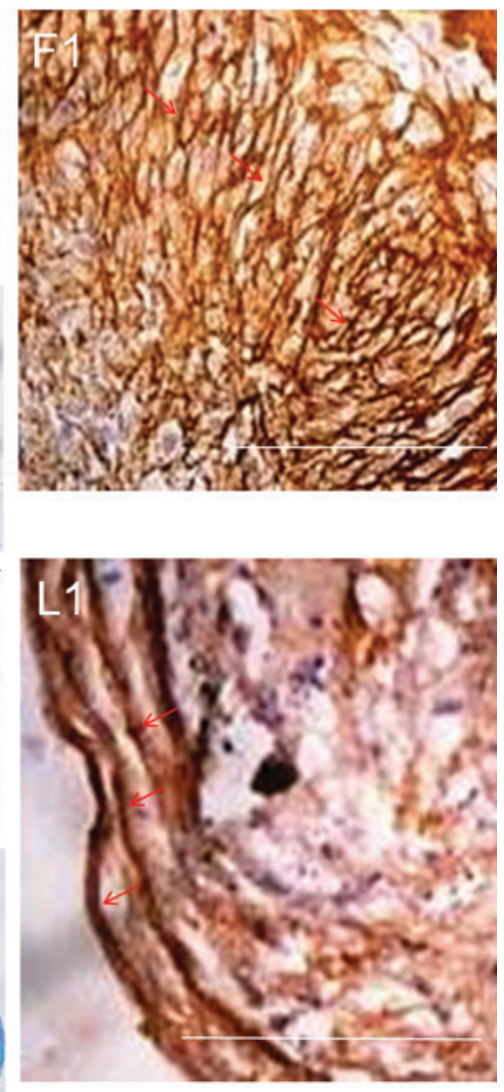

FIG. 1. Histological, histochemical, and immunohistochemical characterization of collagen-hMSC microspheres at different time points during chondrogenic differentiation. (A-D) H\&E staining. (E-H) Immunohistochemistry of type I collagen (Col I). (I-L) Immunohistochemistry of type II collagen (Col II). (M-P) Alcian blue (AB) histochemical staining for glycosaminoglycans. F1, magnified view of F; L1, magnified view of L. Arrows: thick collagen bundles. Scale bar: $100 \mu \mathrm{m}$. hMSC, human mesenchymal stem cells; H\&E, hematoxylin and eosin. Color images available online at www.liebertonline.com/ten.

process in all three subjects, but the change was more dramatic in subject 1 . Two-way ANOVA showed that both the time factor $(p<0.001)$ and the subject factor $(p<0.001)$ significantly affected HYP. Bonferroni's post-hoc tests on the time factor showed that day 21 was significantly different from all other time points $(p \leq 0.038)$, day 14 was significantly different from day $0(p<0.001)$ and day $21(p=0.038)$, day 7 was significantly different from day $0(p=0.002)$, and day 21 $(p<0.001)$ and day 0 were significantly different from all other time points $(p \leq 0.002)$. Moreover, Bonferroni's post-hoc test on subject factor showed that subject 1 was significantly different from the other two subjects $(p<0.001)$.

\section{Increase in type // collagen and GAGs}

Type I collagen was the only scaffold material entrapping the hMSCs within the microsphere. Therefore, any matrix components other than type I collagen should be newly synthesized by the entrapped cells. ECM markers for chondrogenic lineages include type II collagen and proteoglycans. Figure 1I-L shows the immunohistochemical staining of type II collagen in microspheres during chondrogenic differentiation. Negative staining was found before differentiation (Fig. 1I). Slight immunopositive staining of type II collagen was found at day 7 postdifferentiation (Fig. 1J) followed up by an increase in both area and intensity of the staining at day 14 and 21 postdifferentiation (Fig. 1K, L, L1). Quantitative analysis of type II collagen using ELISA confirmed the increasing trend particularly on day 14 and 21 postdifferentiation in all three subjects (Fig. 2D). Two-way ANOVA showed that both the time factor $(p<0.001)$ and the subject factor $(p<0.001)$ significantly affected type II collagen. Bonferroni's post-hoc tests on the time factor showed that both day 21 and day 14 were significantly different from days 7 and $0(p \leq 0.001)$. Moreover, Bonferroni's post-hoc tests on the subject factor showed that all three subjects are significantly different from one another $(p \leq 0.009)$. Minimal staining for GAGs was found in microspheres before chondrogenic differentiation was induced (Fig. 1M). Both area and intensity of the GAG staining were found increased after 7 days (Fig. 1N). Intensive staining for GAG was found at day 14 and 21 postdifferentiation (Fig. 1O, P). Quantitative analysis of GlcUA, which is the regular component of GAG chains, confirmed the trend of continuous increasing proteoglycan content over time in all three subjects (Fig. 2E). Two-way ANOVA showed that both the time factor $(p<0.001)$ and the subject factor $(p=0.02)$ significantly contributed to the changes in GlcUA. Bonferroni's post-hoc 
FIG. 2. Physical and biochemical characterization of collagen-hMSC microspheres at different time points during chondrogenic differentiation. (A) Diameter of microspheres $(n=36-40)$. (B) Type I collagen ( $n=2$ to 4 , each sample is a pool of 5 microspheres). (C) Hyp content $(n=2-3$, each sample is a pool of 10 microspheres). (D) Type II collagen ( $n=3$ to 4 , each sample is a pool of 20 microspheres). (E) Uronic acid content ( $n=3$ to 9$)$. (F) Pyd-to-Hyp ratio $(n=2$ to 3 , each sample is a pool of 10 microspheres). $N=3$ subjects for biochemical characterization. Hyp, hydroxyproline; Pyd, pyridinoline.
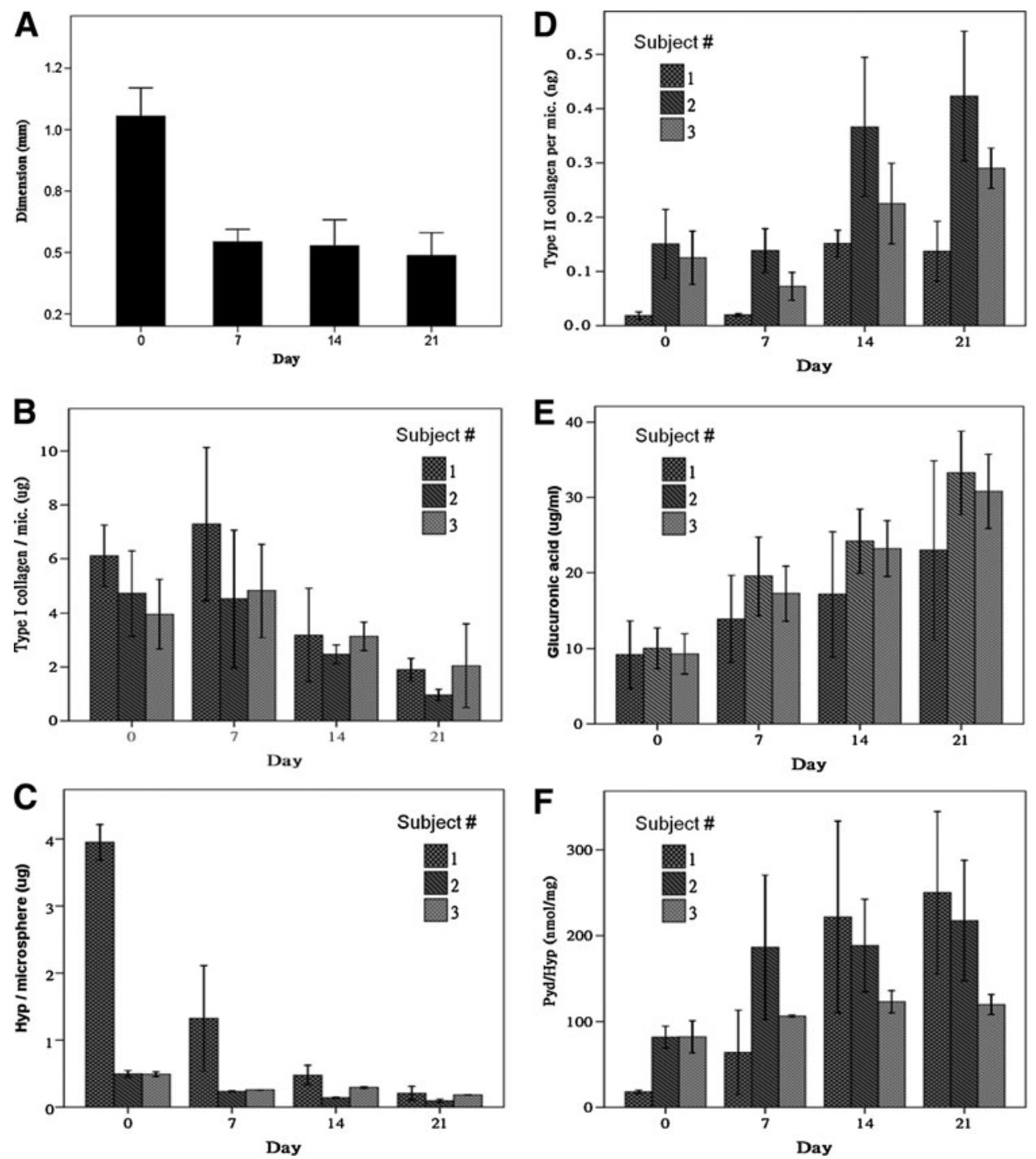

tests on the time factor showed that day 21 was significantly different from all other time points $(p \leq 0.039)$, day 14 was significantly different from day $0(p=0.001)$ and day 21 $(p=0.039)$, day 7 was significantly different from day 21 $(p<0.001)$, and day 0 was significantly different from all time points $(p \leq 0.001)$ but day 7 . Nevertheless, Bonferroni's post-hoc tests on the subject factor did not reveal any significant difference $(p \geq 0.108)$.

\section{Bundle formation and increased collagen crosslinker density}

SEM analysis of the collagen-hMSC microsphere before chondrogenic differentiation showed a highly randomized meshwork of collagen (Fig. 3A). Collagen fibers were found randomly distributed and intercross with each other. Nevertheless, they become more organized as chondrogenic differentiation goes on (Fig. 3B-D). Specifically, closely packed fibers were found, forming thick bundles throughout the microspheres, particularly at days 14 and 21 postdifferentiation (Fig. 3C, D). Such structural changes are highly agreeable with the bundle structures observed in immunohistochemistry of both type I (Fig. 1F, F1) and II (Fig.
1L, L1) collagen, suggesting the enhanced organization of the matrix by the differentiating hMSCs. Moreover, nonfibrous ground substances coating the fibrils were observed throughout the matrix particularly at later time points (Fig. 3C, D). Further, the density of PYD, a major nonreducible collagen crosslinker, has been found significantly increasing over time in all three subjects (Fig. 2F), suggesting an enhanced organization of collagen matrix. This correlates well with the presence of thick bundles observed in SEM (Fig. 3C, D). Two-way ANOVA showed that the time factor $(p=0.002)$ but not the subject factor $(p=0.121)$ significantly affected PYD density. Bonferroni's post-hoc tests on the time factor showed that day $21(p=0.002)$ and day $4(p=0.007)$ were significantly different from day 0 .

\section{Increase in $\mathrm{E}_{r}$}

Figure 4A and B shows the collagen-hMSC microsphere before and after the step change compression assay, which is a rapid, simple, and nondestructive procedure, from which the contact radius between the microsphere and the soft plate was obtained for subsequent calculation. Figure $4 \mathrm{C}$ shows the raw data and the linearly regressed slopes in the 

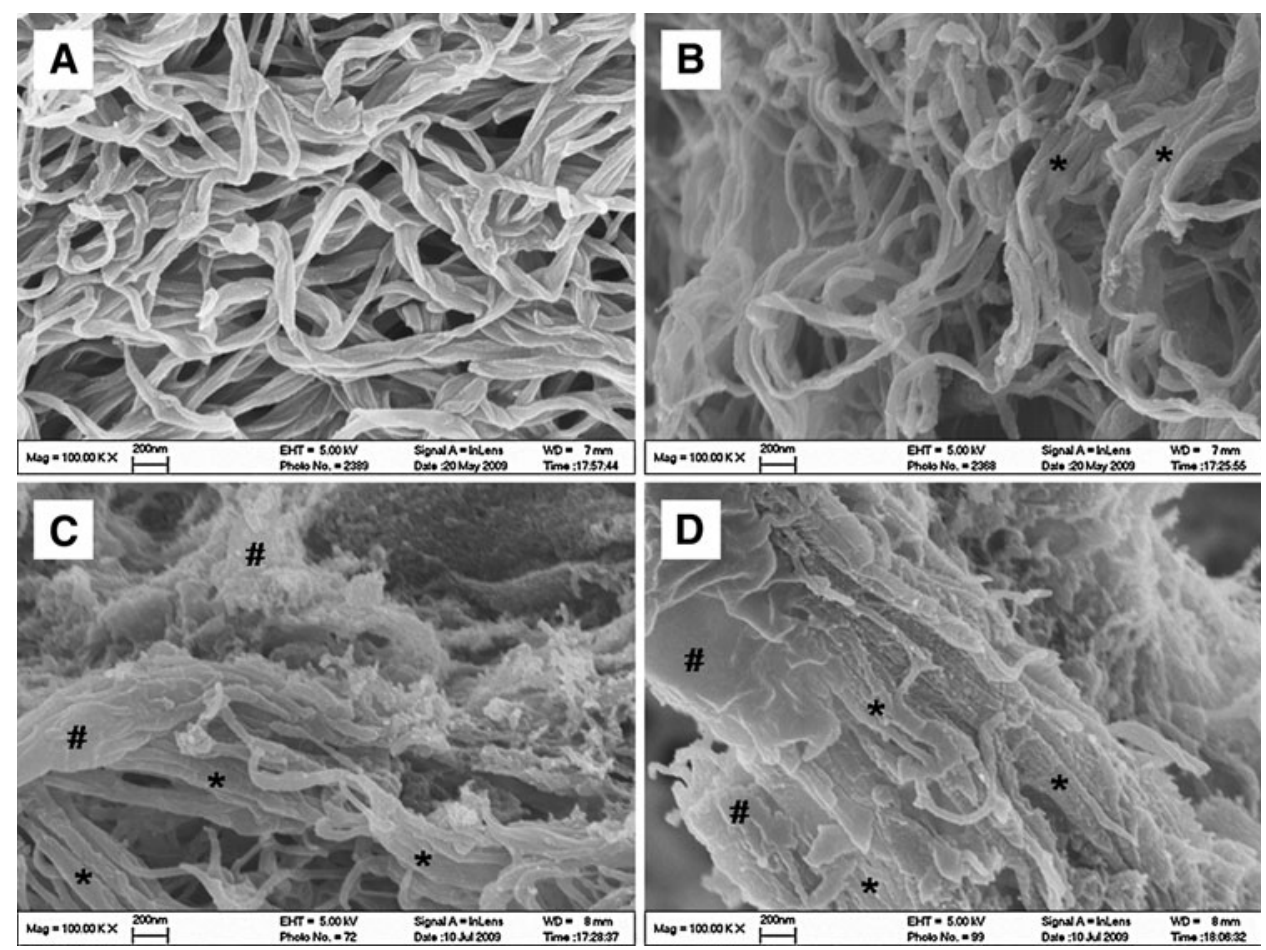

FIG. 3. Scanning electron microscopy of the collagen fibril meshwork of collagenhMSC microspheres at different time points during chondrogenic differentiation. (A) Day 0. (B) Day 7. (C) Day 14. (D) Day 21. Magnifications: $100 \mathrm{~K} \times$; *, parallel bundles; \#, ground substances coating the collagen fibrils.

step-change compression protocol. From which, the difference in slopes of the two compression steps was obtained for subsequent calculation. The mean $E_{\mathrm{r}}$ with standard deviation of the microspheres of three subjects predifferentiation at day 0 was $4.2 \pm 2.5 \mathrm{kPa}$. Upon chondrogenic induction, the mean $E_{\mathrm{r}}$ of the differentiating microspheres from three subjects was increased to $58 \pm 38 \mathrm{kPa}, 65 \pm 44 \mathrm{kPa}$, and $96 \pm 48 \mathrm{kPa}$ on days 7, 14, and 21 postdifferentiation, respectively, accounting for 13.8-, 15.5-, and 22.9-fold of increase. Two-way ANOVA showed that both the time factor $(p<0.001)$ and the subject factor $(p<0.001)$ significantly affected $E_{\mathrm{r}}$. Bonferroni's post-hoc tests showed that day 21 was significantly different from all other time points $(p \leq 0.02)$, day 14 was significantly different from day 21 and $0(p<0.02)$ but not day 7 , day 7 was significantly different from days 21 and 0 $(p<0.003)$ but not day 14 , and day 0 was significantly different from all other time points $(p<0.001)$. Moreover, Bonferroni's post-hoc tests on the subject factor showed that subject 1 was significantly different from the other two subjects $(p<0.001)$.

\section{Association between biochemical compositional parameters and mechanical parameter}

Table 1 shows the nonparametric correlation coefficients with significance values between the compositional parameters and the $E_{\mathrm{r}}$ of the microspheres during differentiation. Specifically, HYP showed a strong negative correlation with $E_{\mathrm{r}}$ in all three subjects $(-0.973,-0.714,-0.905)$, whereas type I collagen also showed a moderate negative correlation in all subjects $(-0.582,-0.479$, and -0.555$)$. On the other hand, type II collagen $(0.510,0.753$, and 0.633$)$ and GAGs $(0.469$, 0.945 , and 0.877 ) showed positive correlation with $E_{\mathrm{r}}$ with moderate to high coefficients, whereas PYD density showed strong positive correlation $(0.733,0.810$, and 0.810$)$. Corre- lation coefficients for HYP, GAGs, and PYD density were statistically significant in all three subjects $(p<0.05)$. Correlation coefficient for type I collagen was statistically significant in one subject $(p=0.029)$ but marginal for the other two subjects $(p=0.077$ and 0.162$)$. Similarly, correlation coefficient for type II collagen was statistically significant in one subject $(p=0.019)$ but marginal in the other two subjects $(p=0.062$ and 0.067$)$.

\section{Discussion}

This study reported the histological, biochemical, structural, and mechanical characterization of collagen-hMSC microspheres during chondrogenic differentiation and demonstrated close correlation between the compositional parameters and the mechanical property of the micropheres. Our results suggested that the differentiating hMSCs are actively remodeling the template type I collagen meshwork in the microspheres, depositing new ECM, including proteoglycans and type II collagen, and organizing the fibrous matrix via collagen crosslinking. This study helps us to better understand how hMSC remodel the microsphere matrix during chondrogenic differentiation and therefore contributes to future development of novel cartilage repair strategies. Finally, this study also illustrated the application of a simple sensitive and nondestructive method monitoring the temporal change in elastic modulus of soft and viscoelastic structures.

\section{Matrix remodeling activities of the differentiating hMSCs contribute to the change in mechanical property of the microspheres}

The first matrix compositional change is the increase in newly deposited cartilage-relevant ECMs, including proteoglycans 


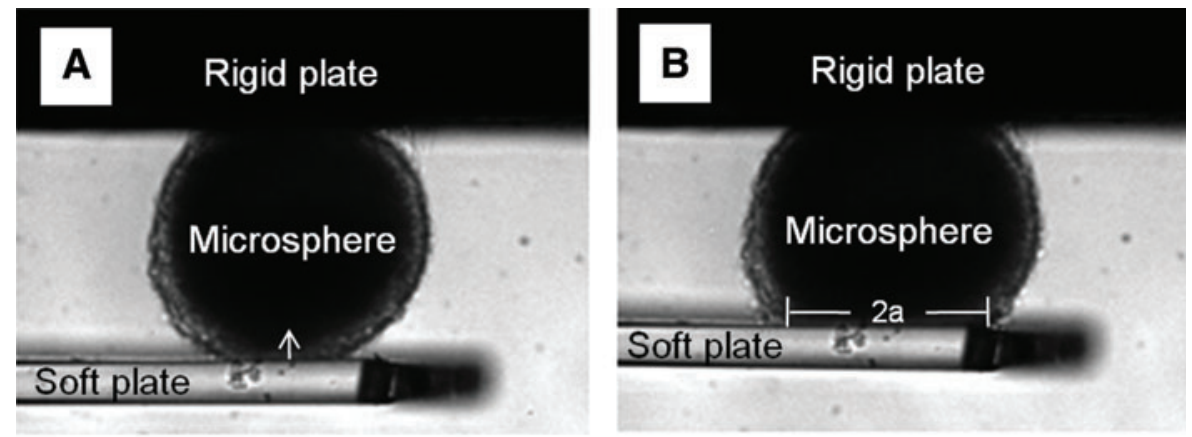

FIG. 4. Mechanical characterization of collagen-hMSC microspheres at different time points during chondrogenic differentiation. (A, B) Phase-contrast images showing a collagen-hMSC microsphere before (A) and after (B) the simple step-change compression assay (arrow, contact point for tracking path of the soft microplate compression; $2 \mathrm{a}$, diameter of the instantaneous contact region between the microsphere and the soft microplate); (C) A representative displacement (micrometers) time (second) curve of collagen-hMSC microsphere during the step-change compression assay $\left(\mathrm{d}^{\prime} \_1\right.$, raw data collected during compression with displacement rate $1 ; \mathrm{d}^{\prime} \_2$, raw data collected during compression with displacement rate 2; linear $\left(\mathrm{d}_{\_}^{\prime} 1\right)$, best fit linear regression line for compression with displacement rate 1 ; linear $\left(\mathrm{d}^{\prime} \_2\right)$, best fit linear regression line for compression with displacement rate 2. (D) $E_{\mathrm{r}}$ of collagen-hMSC microspheres harvested at different time points postdifferentiation (error bars, standard deviations; $n=3$ to 9 per time point). $E_{\mathrm{r}}$, reduced elastic modulus. Color images available online at www.liebertonline.com/ten.
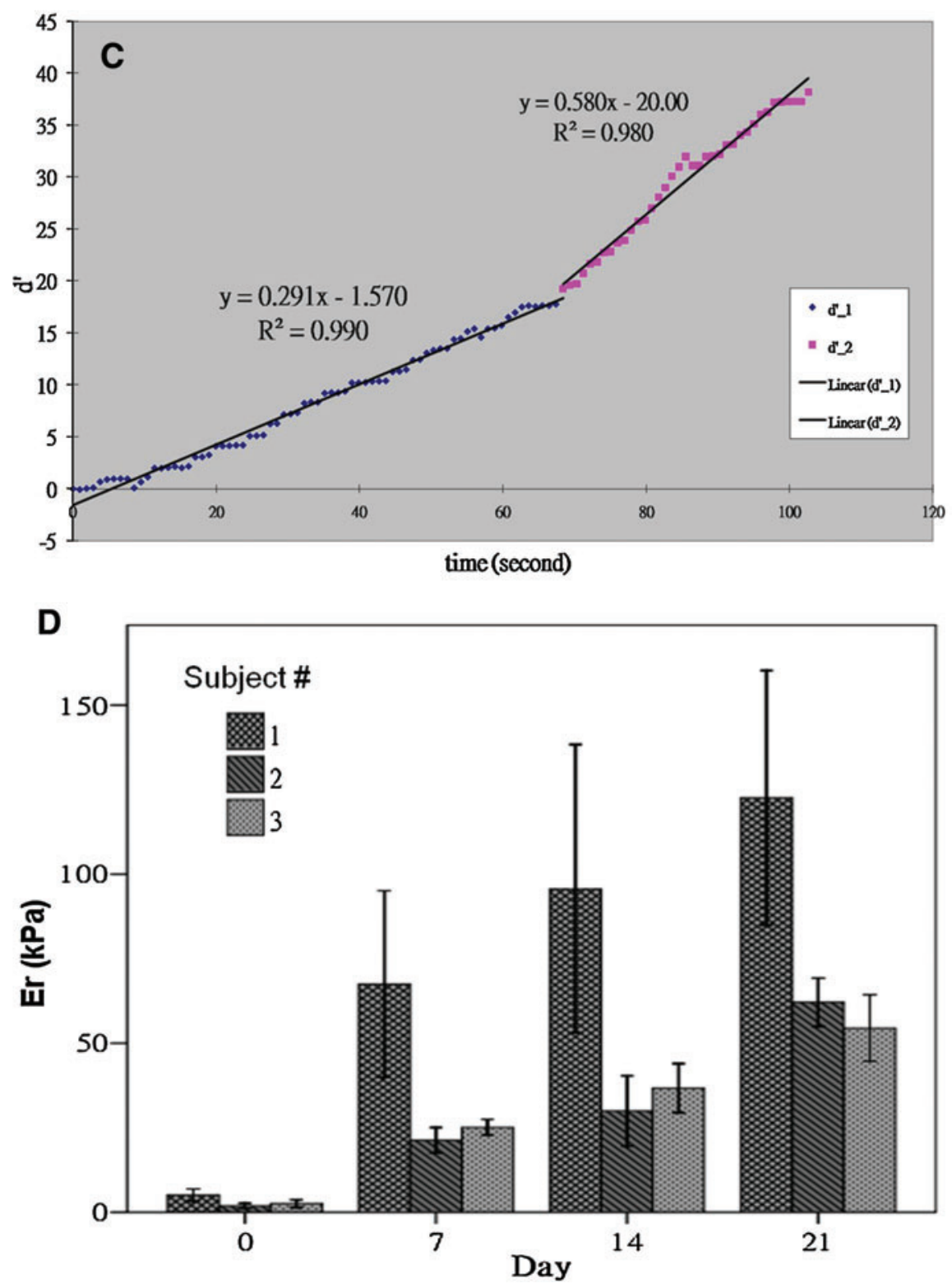

and type II collagen. Despite the differences in types of stem cells and scaffolds used, this characteristic association has been reported in other tissue-engineered constructs. ${ }^{50-52}$ Awad et al. reported a progressive increase in equilibrium shear modulus and complex shear modulus for constructs made of agarose, alginate, and gelatin with adiposed-derived adult stem cells, whereas GAG and HYP contents were found to increase continuously with time ${ }^{50}$; Mauck et al. reported the chondrogenesis of bovine MSCs in agarose culture and demonstrated an increase in Young's modulus and dynamic modulus with collagen and $\mathrm{GAG}^{52}$; the hMSCs seeded silk scaffolds reported by Hofmann et al. also demonstrated a significant increase in the aggregate modulus together with a progressive increase in GAG and expression 
Table 1. Nonparametric Spearman's Rho Correlation Coefficients Between Various Biochemical

Compositional Parameters and the Reduced Elastic Modulus $\left(E_{\mathrm{R}}\right)$ of Human Mesenchymal Stem Cell-Collagen Microspheres Fabricated from Three Subjects During Chondrogenic Differentiation

\begin{tabular}{|c|c|c|c|c|c|c|}
\hline & \multicolumn{2}{|c|}{ Subject no. 1} & \multicolumn{2}{|c|}{ Subject no. 2} & \multicolumn{2}{|c|}{ Subject no. 3} \\
\hline & $\begin{array}{c}\text { Correlation } \\
\text { coefficient with } \mathrm{E}_{r}\end{array}$ & p-Value & $\begin{array}{c}\text { Correlation } \\
\text { coefficient with } \mathrm{E}_{r}\end{array}$ & $\mathrm{p}$-Value & $\begin{array}{c}\text { Correlation } \\
\text { coefficient with } \mathrm{E}_{r}\end{array}$ & $\mathrm{p}$-Value \\
\hline Hydroxyproline (Hyp) & $-0.937^{\mathrm{a}}$ & $<0.001$ & $-0.714^{\mathrm{a}}$ & 0.047 & $-0.905^{\mathrm{a}}$ & 0.002 \\
\hline Type I collagen & $-0.582^{\mathrm{a}}$ & 0.029 & -0.479 & 0.162 & -0.555 & 0.077 \\
\hline Uronic acid (GlcUA) & $0.469^{\mathrm{a}}$ & 0.005 & $0.945^{\mathrm{a}}$ & $<0.001$ & $0.877^{\mathrm{a}}$ & $<0.001$ \\
\hline $\begin{array}{l}\text { Pyridinoline to hydroxyproline } \\
\text { ratio (Pyd/Hyp) }\end{array}$ & $0.733^{\mathrm{a}}$ & 0.016 & $0.810^{\mathrm{a}}$ & 0.015 & $0.810^{\mathrm{a}}$ & 0.015 \\
\hline Type II collagen & 0.51 & 0.062 & $0.753^{\mathrm{a}}$ & 0.019 & 0.633 & 0.067 \\
\hline
\end{tabular}

${ }^{a}$ Data with statistical significance, that is, significant correlation with $E_{\mathrm{r}}$.

of type II collagen. ${ }^{51}$ The second matrix compositional change is related to the structural organization of collagen fibers as demonstrated by both the increase in the density of the collagen crosslinker PYD and the presence of thick collagen bundles in SEM analysis. PYD is generally known to contribute to the tensile properties of tendons ${ }^{46,53}$ and ligaments, ${ }^{54,55}$ and has been demonstrated to associate with both the compressive ${ }^{17}$ and tensile properties ${ }^{56}$ of articular cartilage. The significance of PYD in contributing to the mechanical properties of tissue-engineered constructs has been demonstrated by the significantly lower equilibrium modulus and secant modulus of chondrocyte-seeded alginate beads when exposed to prolonged crosslink inhibition. ${ }^{57}$ The positive association between PYD and mechanical properties in engineered tissue constructs has previously been reported in chondrocyte-seeded polylactic acid and polyglycolic acid. $^{58}$ Moreover, the positive association between HYP normalized PYD and $E_{\mathrm{r}}$ in the microspheres is very relevant to cartilage tissue engineering as type II collagen is more heavily crosslinked than other types. ${ }^{48}$ This may also partially explain the net and significant increase in $E_{\mathrm{r}}$ of the microspheres even though the amount of type II collagen being deposited is minute. A third compositional change is the net decrease in type I collagen and total collagen (HYP). This negative association between $\mathrm{Er}$ and type I collagen or total collagen should be a result of the degradation activity of the differentiating hMSCs. The scaffold material used in fabricating the microspheres is type I collagen, which serves as a degradable template meshwork for hMSCs to remodel as they differentiate. Although the differentiating hMSCs may also synthesize type I collagen, the overall decreasing trend of type I collagen and total collagen suggests that the degradation of the template material outweighs the newly deposited type I collagen if any. Involvement of various enzymes or proteases in matrix remodeling during chondrogenesis has been previously reported. ${ }^{59-63}$ Matrix metalloproteinase 13 is one of the enzymes known to degrade

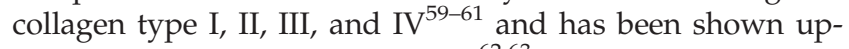
regulated during chondrogenesis. ${ }^{62,63}$ The amount of type I collagen initially used in fabricating the microsphere is way higher (tens of microgram level) than that deposited (nanogram level for type II collagen and microgram level for type I collagen). As a result, the degradation rate of the template material outweighs the deposition rate of any collagen subtype if any. A fourth factor contributing to the increase in $E_{\mathrm{r}}$ of the microspheres is the reduction in size and thus the volume of the microsphere due to hMSC-induced matrix contraction. This leads to a higher matrix density and results in a more compact and solid structure in the microsphere. Nevertheless, the size has reduced only less than half during differentiation, whereas the increase of the $E_{\mathrm{r}}$ was $>24$-fold, suggesting that the compaction effect due to size reduction could not explain the tremendous increase in $E_{\mathrm{r}}$ of the microspheres.

\section{Advantages and limitations of the current study}

The microplate compression technique established in our $\mathrm{lab}^{40}$ presents a simple method in measuring elastic modulus of small soft and viscoelastic structures particularly those hydrogel-based including the commonly used alginate and agarose (data not shown). Utilizing calibrated microplates made of different materials and with different bending stiffness, this method is able to measure structures with a wide range of elastic modulus, ranging from $\sim 100 \mathrm{~Pa}$ for cell-free collagen microspheres ${ }^{40}$ to hundreds of $\mathrm{kPa}$ for microspheres with chondrogenic differentiated hMSCs. ${ }^{40}$ The close correlations between the compositional changes of the microspheres and their elastic modulus established in this work suggest that the microplate method can be used to monitor the progression of chondrogenic differentiation particularly with matrix remodeling activity of hMSCs. Specifically, we can use this method to determine the end point of in vitro manipulation of the microspheres before implantation. Other advantages of this method include its nondestructive nature and the small amount of samples required. The assay is a two-step compression protocol using a very soft and flexible microplate, which will not damage the microsphere at all. Moreover, a single microsphere made of as little as $2.5 \mu \mathrm{L}$ of cell-gel mixture containing hundreds of cells is able to yield a data point, comparing with the biochemical assays where pooling tens of microspheres is required to yield one detectable data point, suggesting the excellent sensitivity of this microplate compression assay. This work also reveals the subject variability in using human cells and suggests that multiple subjects need to be used in this kind of studies. Specifically, significant subject variability was detected in HYP, type II collagen, and Er but not in GAG, type I collagen, and PYD density. Moreover, the compositional mechanical correlation study also revealed the subject variability in type I and II collagen but not in HYP, PYD, and GAGs. The subject variability could be inherent to 
the subjects, and may also be due to changes induced in the cells upon subcultures, insensitivity of certain biochemical assays, and other random errors. One limitation of the current study is that the sample microsphere cannot be used to measure all biochemical and mechanical parameters. On the other hand, for some biochemical tests, pooling of microspheres is required to yield a single data point. As a result, it is impossible to build a statistical model specifically multiple regression, which describes how do the biochemical parameters contribute to the mechanical property of the microspheres. Therefore, separate correlation coefficients between the mechanical property and each of the biochemical parameter were calculated to reveal the associations between each biochemical parameter and the mechanical property. Nevertheless, the relative importance of different biochemical parameters in contributing to the mechanical property of the microspheres cannot be determined.

\section{Elastic modulus of the differentiating collagen-hMSC microspheres is approaching although not achieving that of the native cartilage}

The microplate compression technique was also applied to measure the Young's modulus $(E)$ of rabbit articular cartilage. The mean value was $511 \pm 411 \mathrm{kPa}$, which is comparable to values reported elsewhere. ${ }^{64-67}$ The equation for $E_{r}$ of the microspheres is $E_{r}=\frac{E}{1-v^{2}}=\frac{k}{a}\left(\frac{\Delta \dot{\delta}}{\Delta \dot{\delta}^{\prime}}-1\right)$, which is related to Young's modulus $E$ via $E=E_{r} \times\left(1-v^{2}\right)$. For positivePoisson-ratio materials, Poisson's ratio, $v$, is between 0 and 0.5 , and so $E$ should be smaller than $E_{r}$. The mean $E_{r}$ of the differentiated collagen-hMSC microspheres on day 21 was $96 \mathrm{kPa}$ and the corresponding $E$ would have a value smaller than that, say, $87 \mathrm{kPa}$ if $v$ is assumed to be 0.3 . Thus, the mean $E$ of the differentiated microspheres was only around $20 \%$ of that of native cartilage. As a result, further stimuli for chondrogenesis and new matrix production via prolonged culture in the chondrogenic medium or mechanical stimulation $^{68-70}$ may be needed to further stiffen the engineered microspheres before implantation.

\section{Conclusion}

The compositional mechanical relationship of collagenhMSC microspheres during chondrogenic differentiation has been characterized. Particularly, the temporal change of the reduced elastic modulus of the microspheres was positively associated with newly deposited ECM components, including GAGs and type II collagen, and with increasing matrix organization in terms of collagen crosslinker density during differentiation. The temporal changes in type I collagen and total collagen were negatively associated with the reduced elastic modulus, suggesting the matrix remodeling activity of the differentiating hMSCs. This work illustrates the application of the microplate compression method as a simple sensitive and nondestructive monitoring tool for stem cell differentiation in engineered constructs. This study contributes to future development of stem cell-based cartilage repair.

\section{Acknowledgments}

This work was supported by ITF Fund, ITC, Hong Kong Government (GHP/050/06), University Research Commit- tee, the University of Hong Kong (No: 10206799), and the Strategic Research Theme on Nanotechnology. The authors thank Dr. G.C.F. Chan and Mr. S. Chen for providing the MSCs.

\section{Disclosure Statement}

No competing financial interests exist.

\section{References}

1. Flik, K.R., Verma, N., Cole, B.J., and Bach, B.R. Articular cartilage: structure, biology, and function. In: Williams, R.J., ed. Cartilage Repair Strategies. Totowa, NJ: Human Press Inc.; 2007, pp. 1-12.

2. Huber, M., Trattnig, S., and Lintner, F. Anatomy, biochemistry, and physiology of articular cartilage. Invest Radiol 35, 573, 2000.

3. James, C.B., and Uhl, T.L. A review of articular cartilage pathology and the use of glucosamine sulfate. J Athl Train 36, 413, 2001.

4. Tuan, R.S., and Chen, F.H. Cartilage. In: Battler, A., and Leor, J., eds. Stem Cell and Gene-Based Therapy: Frontiers in Regenerative Medicine. New York: Springer, 2007, pp. 179194.

5. Wang, X., Rackwitz, L., Nöth, U., and Tuan, R.S. Cartilage development, physiology, pathologies, and regeneration. In: Santin, M., ed. Strategies in Regenerative Medicine Integrating Biology with Materials Design. New York: Springer, 2009, pp. 367-449.

6. Smith, G.D., Knutsen, G., and Richardson, J.B. A clinical review of cartilage repair techniques. J Bone Joint Surg Br 87, 445, 2005.

7. Beris, A.E., Lykissas, M.G., Papageorgiou, C.D., and Georgoulis, A.D. Advances in articular cartilage repair. Injury 36 Suppl 4, S14, 2005.

8. Day, B. The indications for arthroscopic debridement for osteoarthritis of the knee. Orthop Clin North Am 36, 413, 2005.

9. Bert, J.M. Abrasion arthroplasty. Op Tech Orthop 11, 90, 2001.

10. Mithoefer, K., Williams, R.J., 3rd, Warren, R.F., Potter, H.G., Spock, C.R., Jones, E.C., et al. The microfracture technique for the treatment of articular cartilage lesions in the knee. A prospective cohort study. J Bone Joint Surg Am 87, 1911, 2005.

11. Hunziker, E.B. Articular cartilage repair: are the intrinsic biological constraints undermining this process insuperable? Osteoarthritis Cartilage 7, 15, 1999.

12. Karataglis, D., Green, M.A., and Learmonth, D.J. Autologous osteochondral transplantation for the treatment of chondral defects of the knee. Knee 13, 32, 2006.

13. Hangody, L., and Fules, P. Autologous osteochondral mosaicplasty for the treatment of full-thickness defects of weight-bearing joints: ten years of experimental and clinical experience. J Bone Joint Surg Am 85A Suppl 2, 25, 2003.

14. Pittenger, M.F., and Martin, B.J. Mesenchymal stem cells and their potential as cardiac therapeutics. Circ Res 95, 9, 2004.

15. Pittenger, M.F., Mackay, A.M., Beck, S.C., Jaiswal, R.K., Douglas, R., Mosca, J.D., et al. Multilineage potential of adult human mesenchymal stem cells. Science 284, 143, 1999.

16. Le Blanc, K., Rasmusson, I., Sundberg, B., Gotherstrom, C., Hassan, M., Uzunel, M., et al. Treatment of severe acute graft-versus-host disease with third party haploidentical mesenchymal stem cells. Lancet 363, 1439, 2004.

17. Ficklin, T., Thomas, G., Barthel, J.C., Asanbaeva, A., Thonar, E.J., Masuda, K., et al. Articular cartilage mechanical and 
biochemical property relations before and after in vitro growth. J Biomech 40, 3607, 2007.

18. Young, A.A., Appleyard, R.C., Smith, M.M., Melrose, J., and Little, C.B. Dynamic biomechanics correlate with histopathology in human tibial cartilage: a preliminary study. Clin Orthop Relat Res 462, 212, 2007.

19. Appleyard, R.C., Burkhardt, D., Ghosh, P., Read, R., Cake, M., Swain, M.V., et al. Topographical analysis of the structural, biochemical and dynamic biomechanical properties of cartilage in an ovine model of osteoarthritis. Osteoarthritis Cartilage 11, 65, 2003.

20. Eyre, D. Collagen of articular cartilage. Arthritis Res 4, 30, 2002.

21. Mayne, R, Mark, K. Collagens of cartilage. In: Brian, K. Hall, ed. Cartilage: Structure, Function, and Biochemistry: Academic Press, 1983. pp. 181-214.

22. Prockop, D.J., and Kivirikko, K.I. Collagens: molecular biology, diseases, and potentials for therapy. Annu Rev Biochem 64, 403, 1995.

23. Ahsan, T., Harwood, F., McGowan, K.B., Amiel, D., and Sah, R.L. Kinetics of collagen crosslinking in adult bovine articular cartilage. Osteoarthritis Cartilage 13, 709, 2005.

24. Bank, R.A., Bayliss, M.T., Lafeber, F.P., Maroudas, A., and Tekoppele, J.M. Ageing and zonal variation in posttranslational modification of collagen in normal human articular cartilage. The age-related increase in non-enzymatic glycation affects biomechanical properties of cartilage. Biochem J 330 (Pt 1), 345, 1998.

25. Eyre, D.R., Dickson, I.R., and Van Ness, K. Collagen crosslinking in human bone and articular cartilage. Age-related changes in the content of mature hydroxypyridinium residues. Biochem J 252, 495, 1988.

26. Fujimoto, D., and Moriguchi, T. Pyridinoline, a nonreducible crosslink of collagen. Quantitative determination, distribution, and isolation of a crosslinked peptide. J Biochem 83, 863, 1978.

27. Ulrich-Vinther, M., Maloney, M.D., Schwarz, E.M., Rosier, R., and O'Keefe, R.J. Articular cartilage biology. J Am Acad Orthop Surg 11, 421, 2003.

28. Laasanen, M.S., Toyras, J., Korhonen, R.K., Rieppo, J., Saarakkala, S., Nieminen, M.T., et al. Biomechanical properties of knee articular cartilage. Biorheology 40, 133, 2003.

29. Stoddart, M.J., Grad, S., Eglin, D., and Alini, M. Cells and biomaterials in cartilage tissue engineering. Regen Med 4, $81,2009$.

30. Tuli, R., Li, W.J., and Tuan, R.S. Current state of cartilage tissue engineering. Arthritis Res Ther 5, 235, 2003.

31. Vinatier, C., Bouffi, C., Merceron, C., Gordeladze, J., Brondello, J.M., Jorgensen, C., et al. Cartilage tissue engineering: towards a biomaterial-assisted mesenchymal stem cell therapy. Curr Stem Cell Res Ther 4, 318, 2009.

32. Chan, B.P., Chan, G.C.F., Wong, H.L., Cheung, P.T., Cheah, K., and Chan, D. Cell-matrix microsphere, associated products, methods for preparation and applications. US Regular Patent Application No. 11/750.

33. Chan, B.P., Hui, T.Y., Yeung, C.W., Li, J., Mo, I., and Chan, G.C. Self-assembled collagen-human mesenchymal stem cell microspheres for regenerative medicine. Biomaterials 28, 4652, 2007.

34. Hui, T.Y., Cheung, K.M., Cheung, W.L., Chan, D., and Chan, B.P. In vitro chondrogenic differentiation of human mesenchymal stem cells in collagen microspheres: influence of cell seeding density and collagen concentration. Biomaterials 29, 3201, 2008.
35. Yeung, C.W., Cheah, K., Chan, D., and Chan, B.P. Effects of reconstituted collagen matrix on fates of mouse embryonic stem cells before and after induction for chondrogenic differentiation. Tissue Eng Part A 15, 3071, 2009.

36. Cheng, H.W., Tsui, Y.K., Cheung, K.M., Chan, D., and Chan, B.P. Decellularization of chondrocyte-encapsulated collagen microspheres: a three-dimensional model to study the effects of acellular matrix on stem cell fate. Tissue Eng Part C Methods 15, 697, 2009.

37. Lee, M., Lo, A.C., Cheung, P.T., Wong, D., and Chan, B.P. Drug carrier systems based on collagen-alginate composite structures for improving the performance of GDNF-secreting HEK293 cells. Biomaterials 30, 1214, 2009.

38. Wong, H.L., Wang, M.X., Cheung, P.T., Yao, K.M., and Chan, B.P. A 3D collagen microsphere culture system for GDNF-secreting HEK293 cells with enhanced protein productivity. Biomaterials 28, 5369, 2007.

39. Chan, B.P., Hui, T.Y., Wong, M.Y., Yip, H.K., and Chan, G.C.F. Formation of injectable and osteoinductive bone-like microparticles using mesenchymal stem cell-collagen microspheres. Tissue Eng Part C 16, 225, 2010.

40. Chan, B.P., Li, C.H., Au-Yeung, K.L., Sze, K.Y., and Ngan, A.H. A microplate compression method for elastic modulus measurement of soft and viscoelastic collagen microspheres. Ann Biomed Eng 36, 1254, 2008.

41. Li, J., Law, H.K., Lau, Y.L., and Chan, G.C. Differential damage and recovery of human mesenchymal stem cells after exposure to chemotherapeutic agents. Br J Haematol 127, 326, 2004.

42. Roughley, P.J., and Lee, E.R. Cartilage proteoglycans: structure and potential functions. Microsc Res Tech 28, 385, 1994.

43. Mort, J.S., and Roughley, P.J. Measurement of glycosaminoglycan release from cartilage explants. Methods Mol Med 135, 201, 2007.

44. Shum, D.K.Y., Chan, S.C.H., and Ip, M.S.M. Neutrophilmediated degradation of lung proteoglycans stimulation by tumor necrosis factor-alpha in sputum of patients with bronchiectasis. Am J Respir Crit Care Med 162, 1925, 2000.

45. Skaggs, D.L., Weidenbaum, M., Iatridis, J.C., Ratcliffe, A., and Mow, V.C. Regional variation in tensile properties and biochemical composition of the human lumbar anulus fibrosus. Spine (Phila Pa 1976) 19, 1310, 1994.

46. Chan, B.P., Fu, S.C., Qin, L., Rolf, C., and Chan, K.M. Pyridinoline in relation to ultimate stress of the patellar tendon during healing: an animal study. J Orthop Res 16, 597, 1998.

47. Herbage, D., Bouillet, J., and Bernengo, J.C. Biochemical and physiochemical characterization of pepsin-solubilized typeII collagen from bovine articular cartilage. Biochem J 161, 303, 1977.

48. Eyre, D.R., Paz, M.A., and Gallop, P.M. Cross-linking in collagen and elastin. Annu Rev Biochem 53, 717, 1984.

49. Ngan, A.H.W., and Tang, B. Response of power-lawviscoelastic and time-dependent materials to rate jumps. J Mater Res 24, 853, 2009.

50. Awad, H.A., Wickham, M.Q., Leddy, H.A., Gimble, J.M., and Guilak, F. Chondrogenic differentiation of adiposederived adult stem cells in agarose, alginate, and gelatin scaffolds. Biomaterials 25, 3211, 2004.

51. Hofmann, S., Knecht, S., Langer, R., Kaplan, D.L., VunjakNovakovic, G., Merkle, H.P., et al. Cartilage-like tissue engineering using silk scaffolds and mesenchymal stem cells. Tissue Eng 12, 2729, 2006.

52. Mauck, R.L., Yuan, X., and Tuan, R.S. Chondrogenic differentiation and functional maturation of bovine mesenchymal 
stem cells in long-term agarose culture. Osteoarthritis Cartilage 14, 179, 2006.

53. Ng, G.Y., Oakes, B.W., Deacon, O.W., McLean, I.D., and Eyre, D.R. Long-term study of the biochemistry and biomechanics of anterior cruciate ligament-patellar tendon autografts in goats. J Orthop Res 14, 851, 1996.

54. Frank, C., McDonald, D., Wilson, J., Eyre, D., and Shrive, N. Rabbit medial collateral ligament scar weakness is associated with decreased collagen pyridinoline crosslink density. J Orthop Res 13, 157, 1995.

55. Woo, S.L., Niyibizi, C., Matyas, J., Kavalkovich, K., WeaverGreen, C., and Fox, R.J. Medial collateral knee ligament healing. Combined medial collateral and anterior cruciate ligament injuries studied in rabbits. Acta Orthop Scand 68, 142, 1997.

56. Williamson, A.K., Chen, A.C., Masuda, K., Thonar, E.J., and Sah, R.L. Tensile mechanical properties of bovine articular cartilage: variations with growth and relationships to collagen network components. J Orthop Res 21, 872, 2003.

57. Bastiaansen-Jenniskens, Y.M., Koevoet, W., de Bart, A.C., van der Linden, J.C., Zuurmond, A.M., Weinans, H., et al. Contribution of collagen network features to functional properties of engineered cartilage. Osteoarthritis Cartilage 16, 359, 2008.

58. Yan, D., Zhou, G., Zhou, X., Liu, W., Zhang, W.J., Luo, X., et al. The impact of low levels of collagen IX and pyridinoline on the mechanical properties of in vitro engineered cartilage. Biomaterials 30, 814, 2009.

59. Deng, S.J., Bickett, D.M., Mitchell, J.L., Lambert, M.H., Blackburn, R.K., Carter, H.L., 3rd, et al. Substrate specificity of human collagenase 3 assessed using a phage-displayed peptide library. J Biol Chem 275, 31422, 2000.

60. Knauper, V., Lopez-Otin, C., Smith, B., Knight, G., and Murphy, G. Biochemical characterization of human collagenase-3. J Biol Chem 271, 1544, 1996.

61. Lemaitre, V., Jungbluth, A., and Eeckhout, Y. The recombinant catalytic domain of mouse collagenase- 3 depolymerizes type I collagen by cleaving its aminotelopeptides. Biochem Biophys Res Commun 230, 202, 1997.

62. Salinas, C.N., and Anseth, K.S. The enhancement of chondrogenic differentiation of human mesenchymal stem cells by enzymatically regulated RGD functionalities. Biomaterials 29, 2370, 2008.

63. Sekiya, I., Vuoristo, J.T., Larson, B.L., and Prockop, D.J. In vitro cartilage formation by human adult stem cells from bone marrow stroma defines the sequence of cellular and molecular events during chondrogenesis. Proc Natl Acad Sci USA 99, 4397, 2002.

64. Athanasiou, K.A., Rosenwasser, M.P., Buckwalter, J.A., Malinin, T.I., and Mow, V.C. Interspecies comparisons of in situ intrinsic mechanical properties of distal femoral cartilage. J Orthop Res 9, 330, 1991.

65. Hoch, D.H., Grodzinsky, A.J., Koob, T.J., Albert, M.L., and Eyre, D.R. Early changes in material properties of rabbit articular cartilage after meniscectomy. J Orthop Res 1, 4, 1983.

66. Julkunen, P., Harjula, T., Marjanen, J., Helminen, H.J., and Jurvelin, J.S. Comparison of single-phase isotropic elastic and fibril-reinforced poroelastic models for indentation of rabbit articular cartilage. J Biomech 42, 652, 2009.

67. Naumann, A., Dennis, J.E., Awadallah, A., Carrino, D.A., Mansour, J.M., Kastenbauer, E., et al. Immunochemical and mechanical characterization of cartilage subtypes in rabbit. J Histochem Cytochem 50, 1049, 2002.

68. Angele, P., Schumann, D., Angele, M., Kinner, B., Englert, C., Hente, R., et al. Cyclic, mechanical compression enhances chondrogenesis of mesenchymal progenitor cells in tissue engineering scaffolds. Biorheology 41, 335, 2004.

69. Schumann, D., Kujat, R., Zellner, J., Angele, M.K., Nerlich, M., Mayr, E., et al. Treatment of human mesenchymal stem cells with pulsed low intensity ultrasound enhances the chondrogenic phenotype in vitro. Biorheology 43, 431, 2006.

70. Waldman, S.D., Spiteri, C.G., Grynpas, M.D., Pilliar, R.M., and Kandel, R.A. Long-term intermittent compressive stimulation improves the composition and mechanical properties of tissue-engineered cartilage. Tissue Eng 10, 1323, 2004

Address correspondence to: Barbara P. Chan, Ph.D.

Tissue Engineering Laboratory

Department of Mechanical Engineering

The University of Hong Kong

Room 711, Haking Wong Building

Pokfulam Road

Hong Kong Special Administrative Region

China

E-mail: bpchan@hkucc.hku.hk

Received: February 08, 2010

Accepted: October 21, 2010

Online Publication Date: November 29, 2010 